\title{
Bench scale electrically driven thermoacoustic heat pump
}

\author{
M.E.H. Tijani, J.A. Lycklama à Nijeholt \\ Energy research Centre of the Netherlands (ECN), P.O. Box 1, 1755 ZG, Petten, The Netherland \\ *Corresponding author's e-mail: tijani@ecn.nl
}

Keywords: Thermoacoustics, Heat pump, Stirling, Energy.

\section{Introduction}

The application of heat pumps in the industry can lead to large energy savings and reduce global warming emissions. Heat pumps can be used to upgrade waste heat. This enables to reuse the huge quantities of energy that would otherwise be rejected to the environment. One of the industrial applications where the application of a heat pump can be beneficial is the distillation process [1-2]. Distillation is one of the largest energy consumers processes in refining and bulk chemical industries. It is estimated that distillation columns consume about $40 \%$ of the total energy used to operate plants in these sectors [3-4]. The distillation process is a very inefficient process as heat at high temperature is supplied to boil a mixture of liquids and most of this heat is released at a lower temperature level during condensation. In a conventional distillation column energy is supplied to the system via the reboiler to evaporate the feed for the separation process. The vapors from the top of the column are liquefied in the (water) cooled condenser. About $95 \%$ of the energy needed for the reboiler leaves the system as waste heat. In a heat pump assisted distillation column, the condenser is linked to the reboiler via the heat pump where the temperature of the vapor from the top of the column is increased and fed to the reboiler where it is condensed. For the Netherlands, the total energy saving potential is estimated to 10-20 PJ/year. The extrapolation to Europe and the world, based on production capacities, leads to more than 100-200 PJ/year for Europe and 300-600 PJ/year for the world.

However, widespread use of large scale heat pumps is not yet common due to the low operation temperatures and limited temperature lifts of conventional heat pumps. Innovative heat pump technologies are needed which can help to overcome these difficulties. One promising innovative heat pump technology is the thermoacoustic heat pump which uses acoustic power to increase the temperature of a waste-heat stream to a higher, useful temperature. Thermoacoustic heat pumps can be electrically or thermally driven and can operate over a large scale of (high) temperatures and can achieve large temperature lifts. This paper presents the design, construction, and test of a bench-scale electrically driven thermoacoustic heat pump (EDTAH) which operates between 60 and $100{ }^{\circ} \mathrm{C}$. The heat pump is designed to deliver $10 \mathrm{~kW}$ of thermal power at $100{ }^{\circ} \mathrm{C}$.

\section{Design and construction of the heat pump}

A schematic illustration of EDTAH is given in Figure 1. The heat pump is designed to operate with helium gas at an average pressure of 50 bar and an operation frequency of 80 $\mathrm{Hz}$. The linear motor delivers the acoustic power needed by the heat pump. A thermal bench using thermal oil simulates the low temperature heat source $\left(50-80^{\circ} \mathrm{C}\right)$ and the high temperature heat sink $\left(100-200^{\circ} \mathrm{C}\right)$. A high temperature heat exchanger (HHX) and a low 
temperature heat exchanger (LHX) are used to connect the heat pump to the heat sink and heat source respectively. The Heat pump is designed and optimized using DeltaEC code.

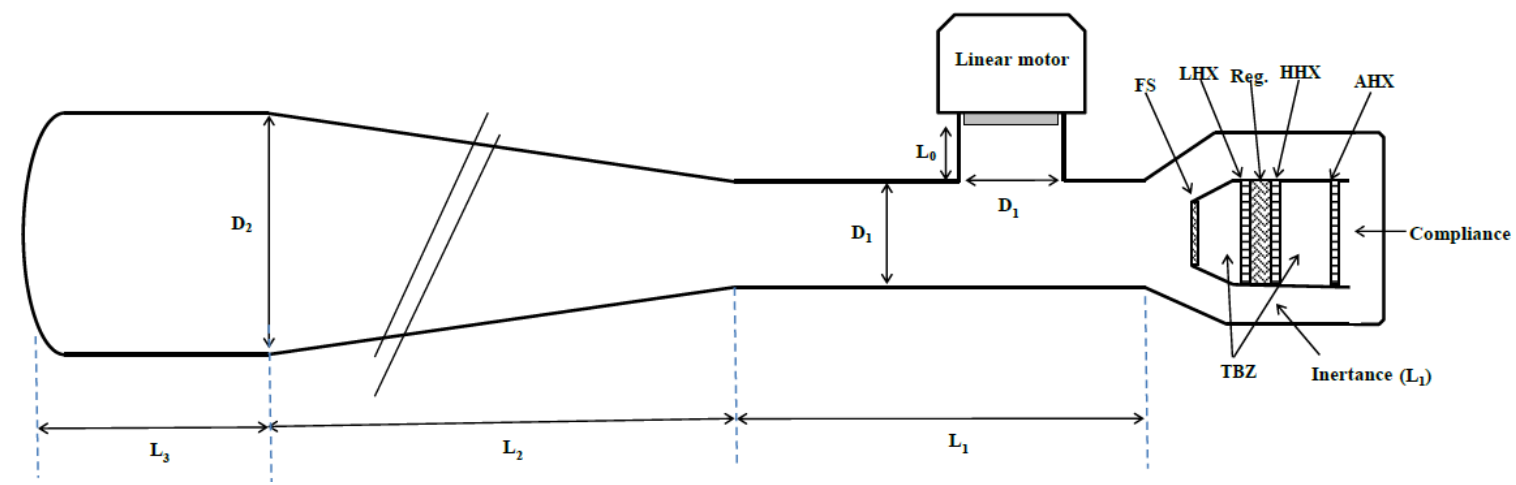

Figure 1: Schematic illustration of the heat pump.

\section{Experimental results}

The first test of the bench scale EDTAH shows that the heat pump delivers about $3 \mathrm{~kW}$ of thermal power at $109{ }^{\circ} \mathrm{C}$ with a COP of 3.02 corresponding to $42 \%$ of the Carnot performance.

\section{References}

[1] Spoelstra, S. and Tijani, M.E.H. 2005, "Thermoacoustic heat pumps for energy savings"” Presented at the seminar "Boundary crossing acoustics" of the Acoustical Society of the Netherlands http://intranet.energy.intra/publicaties/

[2] Kiss, A, Landaeta, S., Ferreira, C (2012), "Mastering Heat pump Selection for Energy Efficient Distillation", Chem. Eng. Trans. 29, (2012), 397-402.

[3] Humprey, J., " Separation processes: playing a critical role”, Chemical Engineering Progress 91 (1995). 31-41.

[4] Mix, T.J. , Dueck, J.S., Weinberg, M. 1978, “Energy conservation in distillation”, Chemical Engineering Progress 74 (1978), 49-55. 